\title{
Cohort Study on the Prevalence and Risk Factors for Delayed Pulmonary Complications in Adults Following Minor Blunt Thoracic Trauma
}

\author{
Miville Plourde, MD, MSc*; Marcel Émond, $\mathrm{MD}^{*} \mathrm{MSc}^{\dagger}$; André Lavoie, $\mathrm{PhD}^{\dagger}$; \\ Chantal Guimont, MD, $\mathrm{PhD}^{\ddagger}$; Natalie Le Sage, MD, MSc ${ }^{\dagger}$; Jean-Marc Chauny, MD, MSc ${ }^{\S}$; \\ Éric Bergeron, MD, $\mathrm{MSc}^{\dagger}$; Laurent Vanier, MD, $\mathrm{PhD}^{\|}$; Lynne Moore, $\mathrm{PhD}^{\dagger}$; \\ Nadine Allain-Boulé, MSc, $\mathrm{MBA}^{\dagger}$; Ramona-Florina Fratu, MSc, $\mathrm{BSc}^{\dagger}$; Maryline Dufresne, $\mathrm{BSc}^{\dagger}$
}

\section{ABSTRACT}

Objectives: The objectives of this study are to determine the prevalence, risk factors, and time to onset of delayed hemothorax and pneumothorax in adults who experienced a minor blunt thoracic trauma.

Method: A prospective cohort of 450 consecutive patients was recruited. Eligible patients had to be over 16 years of age, consulted within 72 hours for a trauma, and available for outpatient follow-up at 2, 7, and 14 days posttrauma. The clinical outcome investigated was the presence of delayed pneumothorax or hemothorax on the follow-up chest x-ray. Outcomes: Delayed hemothorax occurred in $11.8 \% 195 \% \mathrm{Cl}$ 8.8-14.8), and delayed pneumothorax occurred in $0.9 \%(95 \% \mathrm{Cl}$ $0.2-2.3$ ) of participants. During the 14-day follow-up period, $87.0 \%$ of these delayed complications developed in the first week. In the multivariate analysis, the only statistically significant risk factor for delayed complications was the location of fractures on the $x$-ray of the hemithorax. The adjusted odds ratio was $1.52(95 \% \mathrm{Cl} 0.62-3.73)$ for the lower ribs (tenth to twelfth rib), $3.11(95 \% \mathrm{Cl} 1.60-6.08)$ for the midline ribs (sixth to ninth rib), and 5.05 (95\% Cl 1.80-14.19) for the upper ribs (third to fifth rib) versus patients with no fractures. Conclusion: The presence of at least one rib fracture between the third and ninth rib on the x-ray of the hemithorax is a significant risk factor for delayed hemothorax and pneumothorax.

\section{RÉSUMÉ}

Objectifs: Les objectifs de cette étude consistent à déterminer la prévalence, les facteurs de risque, et le délai d'apparition de l'hémothorax et du pneumothorax tardifs chez les adultes ayant subi un traumatisme thoracique mineur fermé.

Méthode: Une cohorte prospective de 450 patients consécutifs a été recrutée. Les patients éligibles devaient être âgés de plus de 16 ans, avoir consulté en deçà de 72 heures pour un traumatisme et être disponibles pour un suivi ambulatoire à 2,7 , et 14 jours suivant le traumatisme. Le résultat clinique recherché était la présence d'hémothorax et de pneumothorax tardifs à la radiographie pulmonaire de contrôle.

Résultats: L'hémothorax tardif est survenu chez 11,8\% (IC ${ }_{95 \%}$ 8,8-14,8) and le pneumothorax tardif chez $0.9 \%\left(\mathrm{IC}_{95 \%} 0,2-\right.$ 2,3\%) des participants. Au cours de la période de suivi de 14 jours, $87,0 \%$ de ces complications tardives se sont manifestées durant la première semaine. En analyse multivariée, le seul facteur de risque de complications tardives statistiquement significatif était la localisation des fractures sur la radiographie de I'hémithorax. Le rapport de cote ajusté se situe à $1,52\left({ }_{1} C_{95 \%}, 0,62-3,73\right)$ pour les côtes inférieures (1012 e côte), à 3,11 (IC $95 \%$ 1,6-6,08) pour les côtes médianes (6$9 \mathrm{e}$ côte), et à 5,05 (IC $95 \% 1,80-14,19)$ pour les côtes supérieures (troisième-cinquième côte) par rapport aux patients sans fracture.

Conclusion: La présence d'au moins une fracture de côte entre la troisième et la neuvième côte à la radiographie de I'hémithorax est un facteur de risque significatif d'hémothorax et de pneumothorax tardifs.

Keywords: delayed hemothorax, delayed pneumothorax, late hemothorax, late pneumothorax, thoracic trauma

From the *Centre hospitalier universitaire de Québec, Hôpital Saint-François d'Assise, Québec, QC; †Trauma-emergency-intensive care department, Centre de recherché FRSQ du CHA, Québec, QC; ‡Reproduction, perinatal health and children's health department, Québec, QC; §Centre de recherché de I'hôpital du Sacré-Coeur de Montréal, Montréal, QC; ॥Hôpital Charles Lemoyne, Greenfield Park, QC.

Correspondence to: Dr. Miville Plourde, Université Laval, Québec, CHUQ - Hôpital Saint-François d'Assise, 10 de I'Espinay Street, QC GIL 3L5; miville.plourde.1@ulaval.ca.

This article has been peer reviewed. 
Thoracic trauma represents 10 to $15 \%$ of trauma encountered in emergency departments. ${ }^{1}$ More than $75 \%$ of patients with rib fractures do not require hospitalization and are treated on an outpatient basis. ${ }^{2}$ Yet they are at risk for developing delayed pulmonary complications. ${ }^{3-9}$ The only prospective cohort study on the topic shows that in the first 2 weeks following a minor blunt thoracic trauma, $7.4 \%$ of patients had developed a delayed hemothorax and $2.0 \%$ a delayed pneumothorax. That study, which examined a low-risk population, identified a correlation between the number of rib fractures and the presence of delayed hemothorax. ${ }^{3}$ Retrospective studies report that the number of rib fractures, age, and the presence of subcutaneous emphysema are the main risk factors for delayed pulmonary complications. ${ }^{4-9}$

At this time, no prospective studies have confirmed these results. There is therefore no consensus in the medical literature regarding follow-up for patients suffering from minor blunt thoracic trauma. ${ }^{3,8-10}$ The purpose of our prospective study was to evaluate the prevalence of delayed hemothorax and pneumothorax, the time of onset, and their risk factors.

\section{METHOD}

\section{Specifications and population}

The patients in this cohort were recruited consecutively from November 20, 2006, to December 31, 2008, at the emergency departments of two university hospitals in the Québec City area: the Hôpital de l'Enfant-Jésus, a level 1 trauma centre, and the Centre Hospitalier de l'Université Laval, a nontrauma designated centre. The ethics committees of these two hospitals approved our research protocol. The results in this article are written and presented based on the Strengthening the Reporting of Observational Studies in Epidemiology (STROBE) Statement.

\section{Data collection}

Eligible patients were identified by an emergency physician on an initial visit to the emergency department following a blunt trauma to the thorax. They needed to present with at least one of the following four factors: 1) pain located primarily in the thoracic cage; 2) an abrasion, contusion, or bruising of the thorax; 3) a suspected rib fracture without radiologic validation; or 4) a rib fracture confirmed by an $\mathrm{x}$-ray of the chest or hemithorax. They also had to be at least 16 years old, able to consent to the study, and available for three follow-up visits at 2, 7, and 14 days posttrauma. Patients were excluded who presented any of the following factors: 1) a lesion not caused by trauma; 2) thoracic trauma that occurred more than 72 hours prior to the visit to the emergency department; 3) trauma requiring hospitalization; 4) a fracture of the first or second rib; 5) a fracture of the sternum; 6) a mediastinal lesion; 7) an initial pulmonary lesion other than atelectasis (hemothorax, pneumothorax, pulmonary contusion, pneumonia); or 8) any other nonthoracic injury requiring orthopedic or surgical treatment or follow-up. These criteria were aimed at retaining trauma isolated to the thorax without initially diagnosed acute complications.

During the initial visit, the emergency physician determined the eligibility of each patient and obtained the patient's consent. The physician completed a structured questionnaire to collate 1) sociodemographic characteristics (age, sex); 2) lifestyle (tobacco use, alcohol consumption); 3) comorbidities (chronic obstructive pulmonary disease, osteoporosis, asthma, diabetes); 4) medications used (acetylsalicylic acid, clopidogrel, warfarin); 5) how the patient arrived at the emergency department (ambulatory or by ambulance); 6) the source of the trauma; and 7) symptoms (thoracic pain, pleuritic pain, dyspnea on exertion, dyspnea at rest, hemoptysis, syncope). The emergency physician conducted a standard physical examination to gather 1) vital signs obtained during triage; 2) thoracic abrasions; 3) thoracic contusions or bruising; 4) bone crepitus; and 5) subcutaneous emphysema. The patient also underwent $\mathrm{x}$-rays of the hemithorax involved and posteroanterior and lateral chest $\mathrm{x}$-rays. The results of the $\mathrm{x}$-rays were interpreted by a radiologist, without any knowledge of the clinical results. The patient was then seen again systematically by the research team composed of a research nurse and an emergency physician at 2, 7, and 14 days posttrauma. All information gathered by the emergency physician was rechecked by the research nurse during the first follow-up visit, without any knowledge of the clinical results. In the event of disagreement between the research nurse and the emergency physician, the nurse reconfirmed the information with the patient, and that information was considered valid. These follow-up dates were adjusted to within 2 days to allow for 
weekends and statutory holidays. On each follow-up visit, the patient underwent a follow-up posteroanterior and lateral chest $\mathrm{x}$-ray, which was interpreted by a radiologist. The delayed complications being looked for were hemothorax and pneumothorax that were not present on the $\mathrm{x}$-ray from the initial visit but that appeared on the follow-up $\mathrm{x}$-ray according to the radiologist's report. More specifically, we considered that any de novo pleural effusion on one of the followup chest $\mathrm{x}$-rays was attributable to a delayed hemothorax. Care of patients during initial and follow-up visits was left to the physician's discretion. The research nurse consulted the record of emergency visits on a daily basis to identify patients who had been missed. Several procedures were implemented to minimize those lost to follow-up and missed patients. First, financial compensation was given to partially compensate for the inconveniences related to travel. Second, a telephone call was made by the research nurse the day before the appointment to maximize patient participation in follow-ups. Third, a systematic follow-up protocol was implemented to minimize loss of time for participants during their visits. Finally, a monthly reminder was given to physicians in training to reduce the number of missed patients.

\section{Statistical analyses}

Descriptive statistics were used to describe the data. The continuous variables were classified by the thresholds identified during a survey of texts regarding age (45 and 65 years) and the number of rib fractures (two and three rib fractures).,3,12-16 For vital signs, the following clinically significant values were used: 1) respiratory rate $\geq 20 / \mathrm{min}, 2$ ) saturation $\leq 93 \%, 3$ ) heart rate $\geq 100 / \mathrm{min}$, 4) systolic blood pressure $\leq 120 \mathrm{~mm}$ $\mathrm{Hg}$, and 5) diastolic blood pressure $\leq 80 \mathrm{~mm} \mathrm{Hg}$.

First, a univariate logistic regression isolated all potentially significant risk factors associated with delayed pulmonary complications $(\alpha \leq 0.15) \cdot{ }^{17}$ Second, a multivariate logistic regression was carried out to identify significant risk factors associated with delayed pulmonary complications $(\alpha \leq 0.05)$. A manual descending logistic regression was used to isolate statistically significant variables. ${ }^{18}$ Recognized risk factors, that is, age and the number of fractured ribs, were also retained in the models. Models were evaluated using the $\mathrm{C}$ statistic to measure discrimination and by the Hosmer-Lemeshow test to measure calibration. ${ }^{19}$ Data were analyzed using $S A S$ version 9.2 (SAS Institute, Cary, NC).

According to data from the study by Misthos and colleagues, $57 \%$ of patients presented with at least one rib fracture. A total of $12.8 \%$ of cases with at least one rib fracture were diagnosed with a delayed hemothorax, compared to $0 \%$ of those who had no rib fractures. ${ }^{3}$ If we conservatively consider that $3 \%$ of patients with at least one rib fracture will develop a diagnosis of delayed hemothorax, we would need to recruit at least 210 patients to obtain a statistically significant difference with a power of $80 \%$ and an $\alpha$ of $5 \%$.

\section{RESULTS}

Of the 1,186 patients evaluated for minor blunt trauma in the emergency departments, 556 were excluded and 101 refused to participate in the study, leaving 529 eligible patients. Of these eligible patients, 50 were not recruited on the initial visit to the emergency department (missed patients), and 29 failed to go to all follow-up visits (patients lost during follow-up), for a study population of 450 patients (Figure 1).

The patients recruited were, on average, older than the missed patients and the patients lost during followup (age 52.5 compared to 45.7 and 42.7, respectively). The first also presented more atelectasis in initial chest $\mathrm{x}$-rays $(10.2 \%$ compared to $0 \%$ and $3.4 \%)$ and had more rib fractures in their $\mathrm{x}$-rays of the hemithorax (0.66 fractures compared to 0.15 fractures and 0.53 fractures). Moreover, these rib fractures were more in the upper ribs (third to fifth rib: $7.1 \%$ compared to $0 \%$ and $0 \%$ ) and the midline ribs (sixth to ninth rib: $24.4 \%$ compared to $8.0 \%$ and $18.2 \%$ ) (Table 1 ).

All patients recruited received at least one follow-up on day 2, 7, or 14 posttrauma after the initial evaluation in the emergency department (100.0\%). During the follow-up period, 288 patients presented on day $2(64.0 \%) 366$ on day $7(81.3 \%), 344$ on day 14 (76.4\%), and 409 on day 7 or 14 (90.9\%). A total of $12.0 \%$ (95\% CI 9.0-15.0) of patients presented with at least one delayed complication during the first 14 days of follow-up: hemothorax appeared in 53 patients (11.8\%; 95\% CI 8.8-14.8) and pneumothorax in 4 patients $(0.9 \%$; $95 \%$ CI $0.2-2.3)$. More than half of the delayed complications were detected in the first 2 days (53.7\%), 33.3\% between days 2 and 7, whereas $13.0 \%$ were diagnosed during the second week posttrauma 


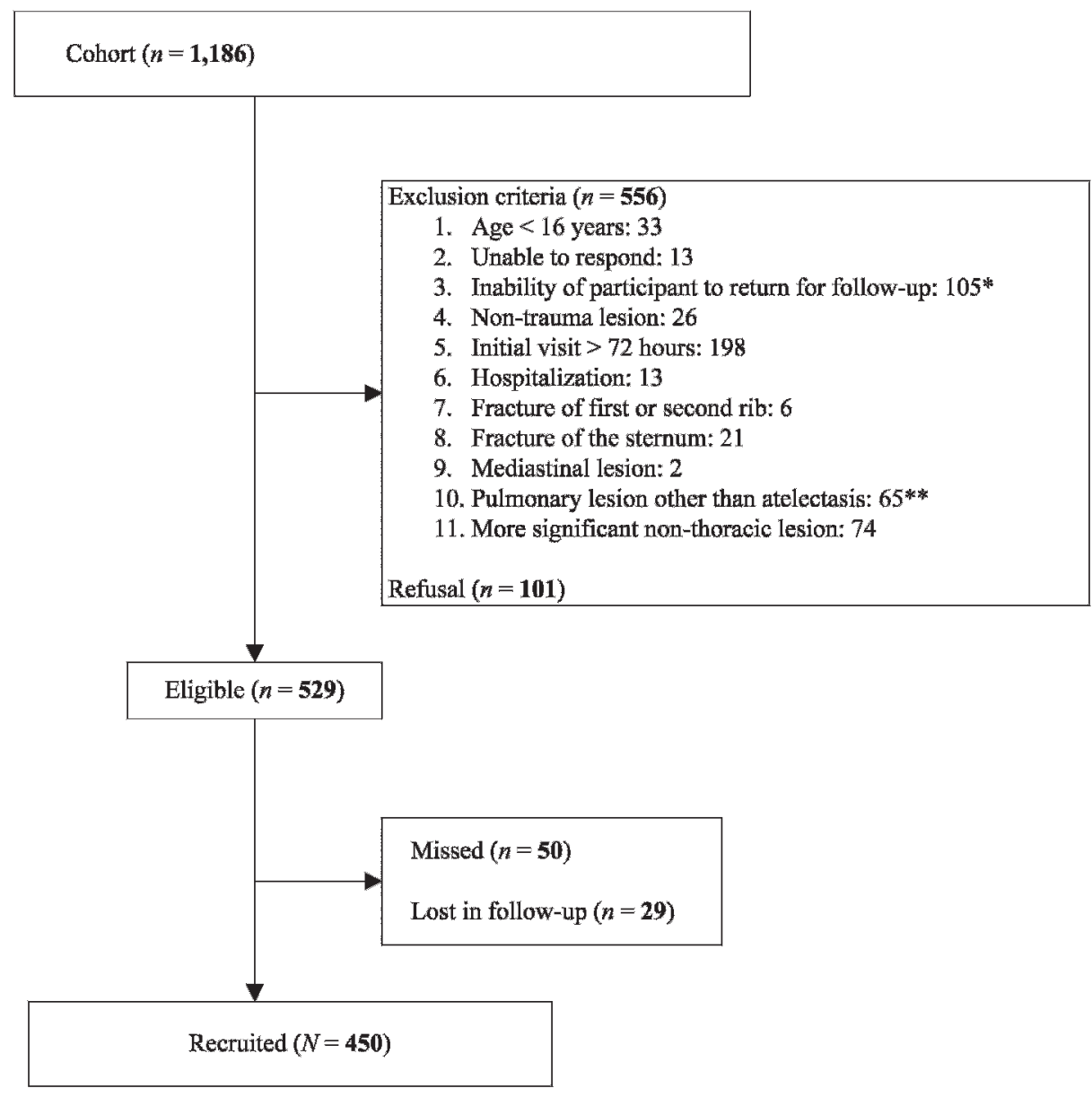

Figure 1. Flow chart. *Patients who were not available for at least one follow-up visit. **Hemothorax, pneumothorax, pulmonary contusion, pneumonia.
(Table 2). Of the patients who developed a delayed complication, four required admission for an average duration of 3.75 days. Three of these required surgical treatment.

In a univariate analysis, the risk of developing a delayed complication increases with age because, compared to patients under the age of 45 , the gross odds ratio is 3.18 (95\% CI 1.35-7.47) for ages 45 to 64 and 4.08 (95\% CI 1.64-10.19) for those over the age of 65 (Table 3). A similar relationship exists for the number of fractured ribs. In effect, compared to patients without fractured ribs, the gross odds ratio increases to 3.76 (95\% CI 1.53-9.29) for patients with two fractured ribs and 9.51 (95\% CI 4.03-22.45) for patients with at least three fractured ribs (see Table 3 ). The same type of relationship exists for the location of the fractured ribs, with the risk increasing as the height of the fractured rib rises. In fact, the gross odds ratio compared to patients who had no fractured ribs increases from 1.53 (95\% CI 0.67-3.48) for lower ribs (tenth to twelfth rib) to 3.22 (95\% CI 1.72-6.01) for midline ribs (sixth to ninth rib) and to 4.84 (95\% CI 2.14-10.99) for upper ribs (third to fifth rib) (see Table 3).

Apart from age, the number of rib fractures, and the location of the fractured ribs, the series of other variables studied included the following statistically significant variables $(\alpha<0.15)$ retained to develop the multivariate model: asthma $(p=0.02)$, diabetes $(p=$ $0.11)$, aspirin $(p=0.03)$, arrival by ambulance $(p=$ $0.04)$, direct blow $(p=0.10)$, syncope $(p=0.11)$, and atelectasis $(p=0.003)$. The multivariate logistic regression shows that the only factor that remains statistically significant is the location of the fractured ribs. In effect, by keeping the recognized risk factors, that is, age over 65 and the presence of at least three fractured ribs, the adjusted odds ratio increases from 1.52 (95\% CI $0.62-3.73$ ) for lower ribs to 3.11 (95\% CI 1.60-6.08) for midline ribs and 5.05 (95\% CI $1.80-14.19)$ for upper ribs. The results are similar if an 


\begin{tabular}{|c|c|c|c|}
\hline Initial visit & Recruited, $n(\%)$ & Missed, $n(\%)$ & Lost in follow-up, $n(\%)$ \\
\hline Number of patients & 450 & 50 & 29 \\
\hline Age $\geq 65$ years & $103(22.9)$ & $6(12.0)$ & $2(6.9)$ \\
\hline Number of males & $276(61.3)$ & $35(70.0)$ & $15(51.7)$ \\
\hline Arrived by ambulance & $122(27.1)$ & $11(23.4)$ & $6(20.7)$ \\
\hline \multicolumn{4}{|l|}{ Vital signs on arrival } \\
\hline$R R \geq 20 / \mathrm{min}$ & $130(28.9)$ & $18(36.0)$ & $7(24.1)$ \\
\hline Saturation $\leq 93 \%$ AA & $36(8.0)$ & $5(10.0)$ & $4(13.8)$ \\
\hline$H R \geq 100 / \mathrm{min}$ & $44(9.8)$ & $8(16.0)$ & $2(6.9)$ \\
\hline $\mathrm{SBP} \leq 120 \mathrm{~mm} \mathrm{Hg}$ & $96(21.3)$ & $11(22.0)$ & $7(24.1)$ \\
\hline $\mathrm{DBP} \leq 80 \mathrm{~mm} \mathrm{Hg}$ & $243(54.0)$ & $30(60.0)$ & $17(58.6)$ \\
\hline \multicolumn{4}{|l|}{ Chest x-ray } \\
\hline Atelectasis & $46(10.2)$ & $0(0.0)$ & $1(3.4)$ \\
\hline \multicolumn{4}{|l|}{ X-ray of hemithorax } \\
\hline$\geq 1$ fracture & $145(32.2)$ & $4(8.0)$ & $6(20.7)$ \\
\hline$\geq 2$ fractures & $71(15.8)$ & $1(2.0)$ & $1(3.4)$ \\
\hline$\geq 3$ fractures & $31(6.9)$ & $0(0.0)$ & $1(3.4)$ \\
\hline$\geq 1$ upper fracture & $32(7.1)$ & $0(0.0)$ & $0(0.0)$ \\
\hline$\geq 1$ midline fracture & $110(24.4)$ & $4(8.0)$ & $5(17.2)$ \\
\hline$\geq 1$ lower fracture & $50(11.1)$ & $0(0.0)$ & $2(6.9)$ \\
\hline
\end{tabular}

age of over 45 years and the presence of at least two fractured ribs are used in the multivariate model. The presence of delayed complications is therefore closely tied to the location of the fractured ribs. Age and the number of fractures do not seem to constitute risk factors for delayed complication (Table 4).

\section{DISCUSSION}

This study has many strengths. First, to our knowledge, this is the largest prospective study in North America of consecutive patients for a population with minor blunt thoracic trauma at an emergency department. Second, this study includes patients over the age of 65 , unlike the study by Misthos and colleagues. ${ }^{3}$ Finally, potential risk factors were gathered without any knowledge of the occurrence of delayed complications.

This study identified a prevalence of $12 \%$ (95\% CI 9.0-15.0) for delayed pulmonary complications at 2 weeks after a minor blunt thoracic trauma, with $11.8 \%$ (95\% CI 8.8-14.8) hemothorax and 0.9\% (95\% CI 0.2-2.3) pneumothorax. This prevalence is comparable to what was noted in the study by Misthos and colleagues, which obtained $7.4 \%$ hemothorax and $2.0 \%$ pneumothorax. ${ }^{3}$ The results of our study corroborate the data in the literature regarding the time of onset of delayed pulmonary complications. In effect, most complications occur less than 7 days posttrauma. ${ }^{3,5-9,20}$ In fact, $87.0 \%$ of delayed complications in our study were diagnosed during the first week and only $13.0 \%$ during the second week posttrauma.

Table 2. Type of delayed complication and time of onset
\begin{tabular}{|lcccc}
\hline & Follow-up \\
Type of delayed complication & 2 days, $n(\%)$ & 7 days, $n(\%)$ & 14 days, $n(\%)$ & At least 1 follow-up in 14 days, $n(\%)$ \\
\hline Hemothorax & $28(52.8)$ & $18(34.0)$ & $7(13.2)$ & $53(11.8)$ \\
Pneumothorax & $2(50.0)$ & $2(50.0)$ & $0(0)$ & $4(0.9)$ \\
Hemothorax or pneumothorax & $29(53.7)$ & $18(33.3)$ & $7(13.0)$ & $54(12.0)$ \\
Patients followed up & $288(64.0)$ & $366(81.3)$ & $344(76.4)$ & $450(100.0)$
\end{tabular}


Risk factors for delayed pulmonary complications following a minor blunt thoracic trauma

\begin{tabular}{|c|c|c|c|}
\hline Characteristic & Total, $n(\%)$ & With complication, $n(\%)$ & Gross odds ratio $(95 \% \mathrm{Cl})$ \\
\hline Number of patients & 450 & 54 & NA \\
\hline$<45$ years & $142(31.5)$ & $7(13.0)$ & 1.00 (reference) \\
\hline $45-64$ years & $205(45.6)$ & $29(53.7)$ & $3.18(1.35-7.47)$ \\
\hline$\geq 65$ years & $103(22.9)$ & 18 (33.3) & $4.08(1.64-10.19)$ \\
\hline Male & $276(61.3)$ & $33(61.1)$ & $0.99(0.55-1.77)$ \\
\hline Arrived by ambulance & $122(27.1)$ & $31(28.9)$ & $1.86(1.03-3.36)$ \\
\hline \multicolumn{4}{|l|}{ Habits and personal history } \\
\hline Smoker/former smoker & $204(58.6)$ & $26(57.8)$ & $0.96(0.51-1.81)$ \\
\hline Alcohol & $29(6.4)$ & $5(9.3)$ & $1.58(0.58-4.34)$ \\
\hline COPD & $14(3.2)$ & 0 & $0.37(0.00-2.25)$ \\
\hline Osteoporosis & $37(7.3)$ & $5(9.6)$ & $1.42(0.52-3.85)$ \\
\hline Diabetes & $40(9.1)$ & $8(15.1)$ & $1.97(0.86-4.54)$ \\
\hline \multicolumn{4}{|l|}{ Medications taken } \\
\hline Acetylsalicylic acid & $71(15.8)$ & $14(25.9)$ & $2.08(1.07-4.07)$ \\
\hline Clopidogrel & $6(1.3)$ & 0 & $0.89(0.00-6.30)$ \\
\hline Warfarin & $19(4.2)$ & $4(7.4)$ & $2.03(0.65-6.36)$ \\
\hline \multicolumn{4}{|l|}{ Source of trauma } \\
\hline Fall $\leq$ the person's height & $155(34.4)$ & $20(37.0)$ & $1.14(0.63-2.05)$ \\
\hline Fall $>$ the person's height & $114(25.3)$ & $16(29.6)$ & $1.28(0.68-2.40)$ \\
\hline Motor vehicle & $105(23.3)$ & $14(25.9)$ & $1.17(0.61-2.25)$ \\
\hline Pedestrian v. vehicle & $2(0.4)$ & 0 & $3.04(0.00-39.30)$ \\
\hline Cyclist v. vehicle & $3(0.7)$ & 0 & $1.91(0.00-17.92)$ \\
\hline Direct blow & $48(10.7)$ & $2(3.7)$ & $0.29(0.07-1.24)$ \\
\hline Other source & $23(5.1)$ & $2(3.7)$ & $0.69(0.16-3.02)$ \\
\hline \multicolumn{4}{|l|}{ Symptoms on arrival } \\
\hline Thoracic pain & $442(98.2)$ & $54(100.0)$ & 1.52 (0.23-infinity) \\
\hline Pleuritic pain & $227(50.4)$ & $24(44.4)$ & $0.76(0.43-1.35)$ \\
\hline Dyspnea on exertion & $92(22.4)$ & $12(23.1)$ & $1.04(0.52-2.08)$ \\
\hline Dyspnea at rest & $31(6.9)$ & $4(7.4)$ & $1.09(0.37-3.26)$ \\
\hline Hemoptysis & $6(1.5)$ & 0 & $0.82(0.00-5.81)$ \\
\hline Syncope & $15(3.7)$ & $4(7.7)$ & $2.61(0.80-8.54)$ \\
\hline \multicolumn{4}{|l|}{ Signs on arrival } \\
\hline $\mathrm{RR} \geq 20 / \mathrm{min}$ & $130(28.9)$ & 19 35.2) & $1.39(0.77-2.54)$ \\
\hline Saturation $\leq 93 \%$ AA & $36(8.0)$ & $4(7.4)$ & $0.91(0.31-2.68)$ \\
\hline$H R \geq 100 /$ min & $44(9.8)$ & $6(11.1)$ & $1.18(0.47-2.93)$ \\
\hline $\mathrm{SBP} \leq 120 \mathrm{~mm} \mathrm{Hg}$ & $96(21.3)$ & $11(20.4)$ & $0.94(0.46-1.89)$ \\
\hline $\mathrm{DBP} \leq 80 \mathrm{~mm} \mathrm{Hg}$ & $243(54.0)$ & $28(51.9)$ & $0.91(0.51-1.60)$ \\
\hline Thoracic abrasion & $20(4.4)$ & 0 & $0.25(0.00-1.46)$ \\
\hline Thoracic contusion & $52(13.8)$ & $5(9.3)$ & $0.61(0.23-1.59)$ \\
\hline Bone crepitus & $13(2.9)$ & $1(1.9)$ & $0.60(0.08-4.74)$ \\
\hline \multicolumn{4}{|l|}{ Chest x-ray } \\
\hline Atelectasis & $46(10.2)$ & $12(22.2)$ & $3.04(1.46-6.32)$ \\
\hline \multicolumn{4}{|c|}{$\begin{array}{l}\text { X-ray of hemithorax: } \\
\text { presence or absence of fractured ribs }\end{array}$} \\
\hline$\geq 1$ fractured rib & $145(32.2)$ & 35 (64.8) & $4.45(2.42-8.21)$ \\
\hline \multicolumn{4}{|l|}{$\begin{array}{l}\text { X-ray of hemithorax: } \\
\text { number of fractured ribs }\end{array}$} \\
\hline No fractures & $305(67.8)$ & $19(35.2)$ & 1.00 (reference) \\
\hline 1 fractured rib & $74(16.4)$ & $15(27.8)$ & $3.83(1.84-7.96)$ \\
\hline 2 fractured ribs & $40(8.9)$ & $8(14.8)$ & 3.76 (1.53-9.29) \\
\hline$\geq 3$ fractured ribs & $31(6.9)$ & $12(22.2)$ & $9.51(4.03-22.45)$ \\
\hline
\end{tabular}




\begin{tabular}{|c|c|c|c|}
\hline Characteristic & Total, $n(\%)$ & With complication, $n(\%)$ & Gross odds ratio $(95 \% \mathrm{Cl})$ \\
\hline \multicolumn{4}{|l|}{$\begin{array}{l}\text { X-ray of hemithorax: } \\
\text { location of fractured ribs }\end{array}$} \\
\hline No fractures & $305(67.8)$ & $19(35.2)$ & 1.00 (reference) \\
\hline Upper ribs (ribs $3,4,5$ ) & $32(7.1)$ & $13(24.1)$ & $4.84(2.14-10.99)$ \\
\hline Midline ribs (ribs 5, 7, 8, 9) & $110(24.4)$ & $28(51.8)$ & $3.22(1.72-6.01)$ \\
\hline Lower ribs (ribs 10, 11, 12) & $50(11.1)$ & $10(18.5)$ & $1.53(0.67-3.48)$ \\
\hline
\end{tabular}

A review of past literature regarding risk factors indicated that age and the number of fractured ribs are significant risk factors for delayed complications..$^{3-9}$ Our prospective study provides a different angle by examining a new variable, the location of the fractures, which makes the previous factors secondary. In effect, after adjusting for all potentially confounding factors, the only risk factor that remains statistically significant is the location of the fractured ribs. It would seem that it is not the number but the location of the fractures that determines the risk of delayed complications. Our study is the first to show the importance of the location of the fractured ribs, as evaluated by an x-ray of the hemithorax, in terms of the risk of delayed pulmonary complications. Our preliminary data show that fractures of the third to ninth ribs are a risk factor for delayed pulmonary complications. Another study on acute rather than delayed complications identified fractures of the ninth to twelfth ribs as a predictive factor for acute intra-abdominal complications but did not demonstrate the relationship between the location of the fractured ribs and the presence of acute

\begin{tabular}{|c|c|c|}
\hline Characteristic & Odds ratio $(95 \% \mathrm{Cl})$ & $p$ value \\
\hline \multicolumn{3}{|l|}{ Age } \\
\hline$<65$ years & 1.00 (reference) & \\
\hline$\geq 65$ years & $1.62(0.84-3.13)$ & 0.15 \\
\hline \multicolumn{3}{|c|}{ Number of fractured ribs } \\
\hline$<3$ & 1.00 (reference) & \\
\hline$\geq 3$ & $0.95(0.29-3.07)$ & 0.93 \\
\hline \multicolumn{3}{|c|}{ Location of fractured ribs } \\
\hline None & 1.00 (reference) & \\
\hline Upper ribs & $5.05(1.80-14.19)$ & 0.002 \\
\hline Midline ribs & $3.11(1.60-6.08)$ & 0.0009 \\
\hline Lower ribs & $1.52(0.62-3.73)$ & 0.36 \\
\hline
\end{tabular}

intrathoracic complications. ${ }^{21}$ Therefore, it seems that the location of the fractured ribs plays a role in the level of acute intra-abdominal complications and delayed pulmonary complications.

Despite its strengths, however, our study presents certain limitations. First, a total of $14.9 \%$ of patients in the cohort were missed or lost to follow-up. The condition of these patients was, on average, less severe than that of the patients analyzed. It is therefore not very likely that these missed or lost patients would have reduced the identification of risk factors. However, this selection bias may have resulted in a slight overestimation of the prevalence of delayed complications within the cohort because they were low-risk patients. Second, $76.4 \%$ of patients presented for follow-up on day 14. It is therefore possible that we missed delayed complications. Nonetheless, $90 \%$ of the cohort had at least one follow-up on day 7 or 14, thus minimizing this risk given that the majority of complications occur during the first week following a minor blunt thoracic trauma. Third, we did not measure interrater agreement for the measurement of the dependent and independent variables being studied. Fourth, it is possible that certain rare potential risk factors may have been excluded from the model due to the low prevalence within this cohort, despite their possible predictive effect. Finally, delayed pulmonary complications are defined by a radiologic, not a clinical, diagnosis. Only a minority of surgical complications required surgical treatment, which differs from the study by Misthos and colleagues, in which $84.6 \%$ of delayed hemothorax cases required surgical treatment, compared to $42.9 \%$ of delayed pneumothorax cases. ${ }^{3}$ Our study specifications were not intended to evaluate the relevance of siphoning off or not siphoning off these delayed surgical complications, and they were left to the discretion of the attending physician. Given the 
prevalence, a future study should examine the clinical repercussion of these radiologic anomalies.

\section{CONCLUSION}

Delayed hemothorax is a frequent consequence of minor blunt thoracic trauma. It generally occurs less than 2 weeks after the incident. On $x$-rays of the hemithorax, the presence of rib fractures between the third and ninth ribs is a significant risk factor for delayed complications.

Competing interests: None declared.

\section{REFERENCES}

1. Ziegler DW, Agarwal NN. The morbidity and mortality of rib fractures. I Trauma 1994;37:975-9, doi:10.1097/ 00005373-199412000-00018.

2. Cherry DK, Woodwell DA. National Ambulatory Medical Care Survey: 2000 summary. Adv Data 2005;5:1-32.

3. Misthos P, Kakaris S, Sepas E, et al. A prospective analysis of occult pneumothorax, delayed pneumothorax and delayed hemothorax after minor blunt thoracic trauma. Eur 7 Cardiothorac Surg 2004;25:859-64, doi:10.1016/j.ejcts.2004. 01.044 .

4. Holcomb JB, McMullin NR, Kozar RA, et al. Morbidity from rib fractures increases after age 45. $7 \mathrm{Am}$ Coll Surg 2003;196:549-55, doi:10.1016/S1072-7515(02)01894-X.

5. Lu MS, Huang YK, Liu YH, et al. Delayed pneumothorax complicating minor rib fracture after chest trauma. Am 7 Emerg Med 2008;26:551-4, doi:10.1016/j.ajem.2007.08.022.

6. McLoughlin R, Mulcahy R, Kent P, et al. Haemothorax after rib fracture - incidence, timing and prediction. Ir 7 Med Sci 1987;156:117-9, doi:10.1007/BF02954634.

7. Ross RM, Cordoba A. Delayed life-threatening hemothorax associated with rib fractures. I Trauma 1986;26:576-8, doi:10.1097/00005373-198606000-00018.

8. Sharma OP, Hagler S, Oswanski MF. Prevalence of delayed hemothorax in blunt thoracic trauma. Am Surg 2005;71: 481-6.
9. Simon BJ, Chu Q, Emhoff TA, et al. Delayed hemothorax after blunt thoracic trauma: an uncommon entity with significant morbidity. 7 Trauma 1998;45:673-6, doi:10.1097/ 00005373-199810000-00005.

10. Shields JF, Emond M, Guimont C, et al. Acute minor thoracic injuries: evaluation of practice and follow-up in the emergency department. Can Fam Phys 2010;56:e117-24.

11. Vandenbroucke JP, von Elm E, Altman DG, et al. Strengthening the Reporting of Observational Studies in Epidemiology (STROBE): explanation and elaboration. Epidemiology 2007;18: 805-35, doi:10.1097/EDE.0b013e3181577511.

12. Barnea Y, Kashtan H, Skornick Y, et al. Isolated rib fractures in elderly patients: mortality and morbidity. Can 7 Surg 2002;45:43-6.

13. Bulger EM, Arneson MA, Mock CM, et al. Rib fractures in the elderly. I Trauma 2000;48:1040-6; discussion 6-7, doi:10.1097/00005373-200006000-00007.

14. Lee RB, Sass SM, Morris JA Jr, et al. Three or more rib fractures as an indicator for transfer to a level I trauma center: a population-based study. 7 Trauma 1990;30:689-94, doi:10.1097/00005373-199006000-00006.

15. Sirmali $M$, Turut H, Topcu S, et al. A comprehensive analysis of traumatic rib fractures: morbidity, mortality and management. Eur 7 Cardiothorac Surg 2003;24:133-8, doi: 10.1016/S1010-7940(03)00256-2.

16. Testerman GM. Adverse outcomes in younger rib fracture patients. South Med 7 2006;99:335-9, doi:10.1097/01.smj. 0000203815.29757.d3.

17. Harrell FE Jr, Lee KL, Califf RM, et al. Regression modelling strategies for improved prognostic prediction. Stat Med 1984;3:143-52, doi:10.1002/sim.4780030207.

18. Katz MH. Multivariate analysis: a practical guide for clinicians. New York: Cambridge University Press; 2006.

19. Hosmer DW, Lemeshow S. Applied logistic regression. New York: Wiley-Interscience; 2000.

20. Bundy DW, Tilton DM. Delayed hemothorax after blunt trauma without rib fractures. Mil Med 2003;168:501-2.

21. Al-Hasani A, Abdulrahman H, Afifi I, et al. Rib fracture patters predict thoracic chest wall and abdominal solid organ injury. Am Surg 2010;7:6888-91. 